Portland State University

PDXScholar

1989

\title{
Toward predicting completion of substance abuse treatment
}

Rebecca Lee Bragg

Portland State University

Follow this and additional works at: https://pdxscholar.library.pdx.edu/open_access_etds

Part of the Psychology Commons, and the Substance Abuse and Addiction Commons Let us know how access to this document benefits you.

\section{Recommended Citation}

Bragg, Rebecca Lee, "Toward predicting completion of substance abuse treatment" (1989). Dissertations and Theses. Paper 3860.

https://doi.org/10.15760/etd.5744

This Thesis is brought to you for free and open access. It has been accepted for inclusion in Dissertations and Theses by an authorized administrator of PDXScholar. Please contact us if we can make this document more accessible: pdxscholar@pdx.edu. 
AN ABSTRACT OF THE THESIS OF Rebecca Lee Bragg for the Master of Science in Psychology presented August 1, 1989.

Title: Toward Predicting Completion of substance Abuse Treatment.

APPROVED BY THE MEMBERS OF THE THESIS COMMITTEE:

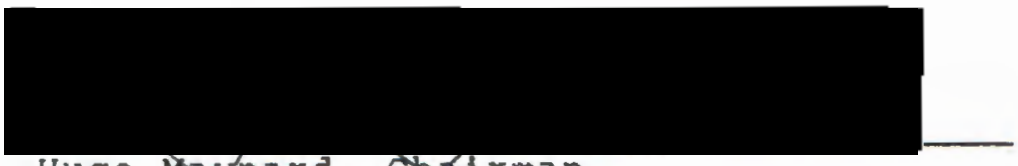

Hugo Maynard, Chairman

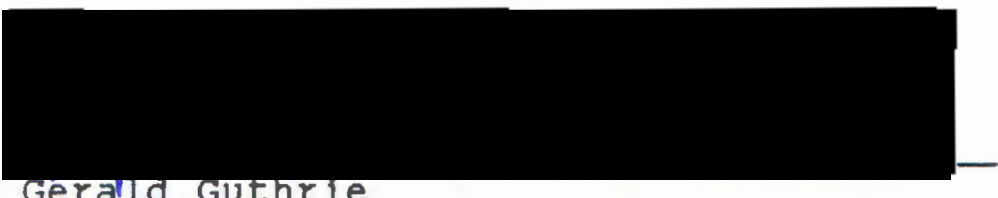

Gerald Guthrie

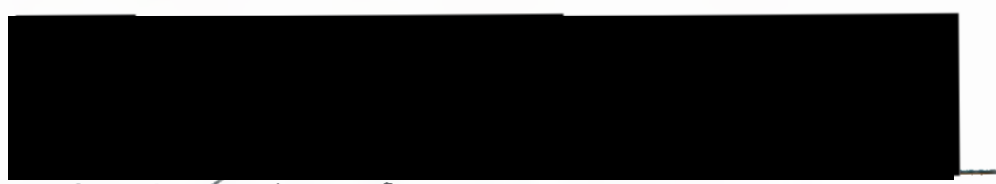

Robert Lockwood

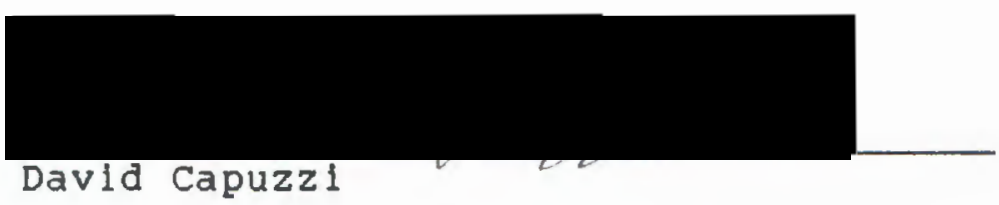

This investigation attempts to identify factors which influence whether or not someone is likely to drop out of a chemical dependency treatment program. Dropping out is defined as someone who leaves treatment against medical advice. 
The subjects were patients from a private, non-profit, medically based, residential program. Nine demographic characteristics were abstracted from the charts on file for the patients at the treatment center. Two groups of 45 patients each were selected from the inpatient population. One group, the completed Treatment group, comprised patients who had completed the 28 day program. The second group, the AMA Discharge group, comprised patients who dropped out of treatment within the first 4 to 10 days. The demographic characteristics analyzed were gender, number of drugs used by the patient, drug preference, method of admission, treatment history, marital success, social status, dependents 1 iving at home, and education.

A stepwlse discriminant analysis using the sPss-x statistical package was performed to select the best linear, weighted combination of variables which would produce the greatest discrimination between the two groups. The variables selected by the discriminant analysis were drug preference, treatment history, marital success, and social status. These four varlables proved to be significant in accounting for the greatest proportion of total variance at a signiflcance level of .0559 .

The discriminant function was used to classify the individual subjects according to their highest probability of membership into each group. By comparing actual and predicted group memberships, using the original sample, the validity of the discriminant function and discriminant 
variables was empirically measured. People who completed treatment were correctly predicted $68.9 \%$ of the time to complete treatment. Those who left against medical advice were correctly predicted $64.4 \%$ of the time to drop out of treatment. The percent of all "grouped" cases correctly classified by the discriminant analysis was $66.67 \%$.

The variables selected for this study do not predict dropping out of treatment at a level of certainty which is clinically useful. Even if the results obtained by this study accurately predicted dropping out of treatment $100 \%$ of the time, the focus must not be on discriminantly choosing to admit those who will not drop out of treatment, but instead on what the agency can do to enable a person to complete treatment. This may sometimes require the redesign of treatment programs.

Further research, studying the role of variables which represent the patient's interaction with the treatment program rather than variables which simply identify static characteristics of a subject, is needed to more fully identify how a treatment agency might facilitate treatment completion. 


\section{TOWARD PREDICTING COMPLETION OF SUBSTANCE ABUSE TREATMENT}

by

REBECCA LEE BRAGG

A thesis submitted in partial fulfillment of the requirements for the degree of

\section{MASTER OF SCIENCE \\ in \\ PSYCHOLOGY}

Portland state University

1989 
TO THE OFFICE OF GRADUATE STUDIES:

The members of the committee approve the thesis of Rebecca Lee Bragg presented August 1, 1989.

\section{Hugo Maynard, Chaxrman}
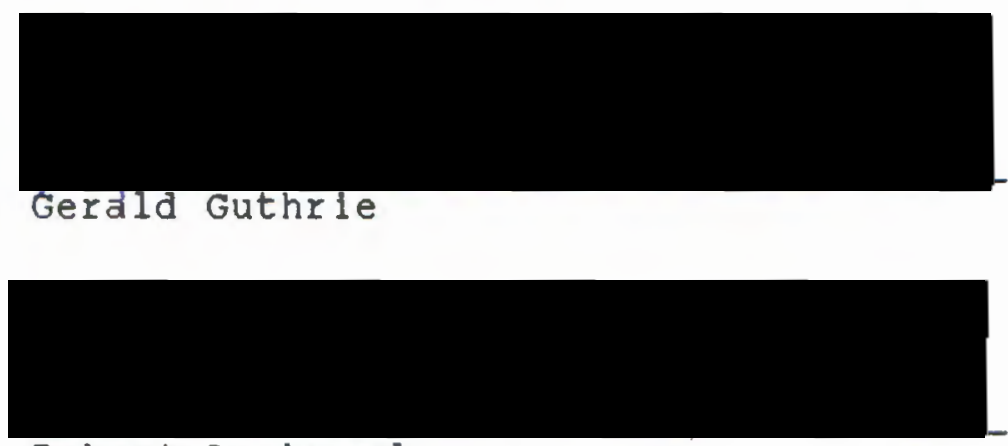

Robert Lockwood

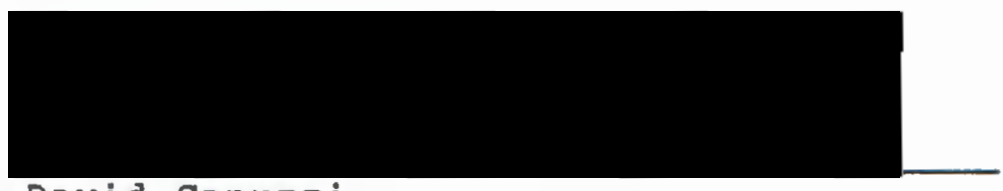

David Capuzzi

APPROVED :

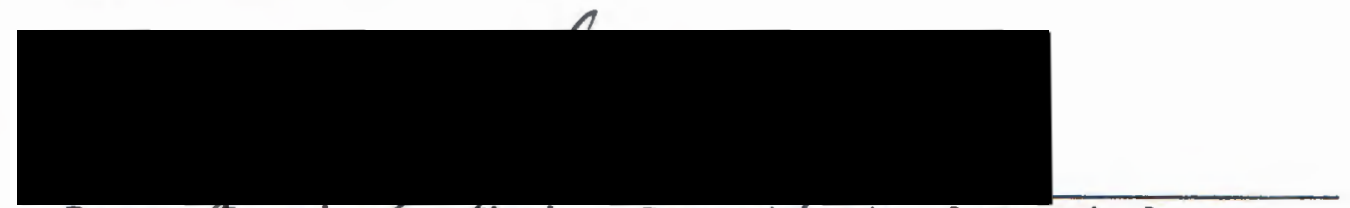

Roger pennings, Chair, Departhent of Psychology

C. Wlllam Savery, Anterim Vice provost for Graduate studies and Research 


\section{ACKNOWLEDGEMENTS}

I want to thank Dr. Hugo Maynard. When I felt the doubt and fear that was so much a part of the endeavor he gently and clearly defined the process and showed me the next step. Without him beside me I wonder if I would have completed this thesis.

I also want to thank Dr. Gerald Guthrie and Bob Lockwood, J.D. for challenging my tunnel vision and my humanity - also for their flexibility and support as I rushed to complete this study in time.

I also thank Debra strugar for believing in me, no matter what.

And of course, I thank my family for loving me as they waited. 
TABLE OF CONTENTS

PAGE

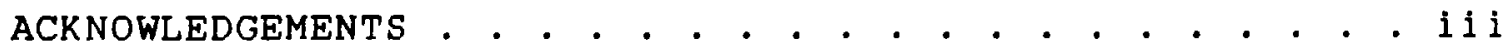

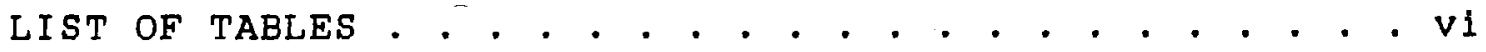

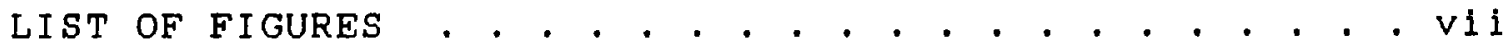

CHAPTER

I INTRODUCTION • . . • . . . • . • . . . . . . 1

Review of the Literature . . . . . . . 2

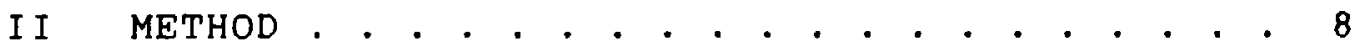

subjects . . . . . . . . . . . . . 8

Treatment Milieu . . . . . . . . . 8

Treatment staff. . . . . . . . . 12

Procedure . . . . . . . . . . . . 12

Measures . . . . . . . . . . . . 13

II RESULTS • • • • • • • • • • • • • • • • . 16

Discriminant Analysis . . . . . . . 18

Discriminant Functions . . . . . . . 23

IV DISCUSSION . . . . . . . . . . . . . . . 26

Implications for Further study . . . . 30

Conclusions . . . . . . . . . . 33 
REFERENCES • . • . . . . . . . . . . . . . . . 35

APPENDICES • . • . . . . . . . . . . . . . . . 37

A DESCRIPTION OF THE NUMERICAL RANKING OF

EACH VARIABLE . . . . . . . . . . . . . 37

B LIST OF THE TWELVE STEPS (ALCOHOLICS

ANONYMOUS, 1976) • . . . . . . . . . . . . 39 


\section{LIST OF TABLES}

TABLE

PAGE

I Group Mean, standard Deviation and $t$-Test for All Variables . . . . . . . . . . . 16

I Wilk's Lambda, F-Ratio and significance for Each Variable Before the First step of Discriminant Analysis . . . . . . . . . 19

II Test of Equality of Group Covariance Using Box's M. . . . . . . . . . . . . . 20

IV Pooled within-Groups correlation Matrix . . . . 22

$V \quad$ Wilk's Lambda and significance for

Discriminating Variables After 4 steps . .23

VI standardized Canonical Discriminant Function Coefficients . . . . . . . . . . . . . 24

VII Results of Discriminant classification of Subjects Into Groups . . . . . . . . . 25

VIII ANOVA of Discriminant scores Differentiating Both Groups . . . . . . . . . . . . 28 


\section{LIST OF FIGURES}

F I GURE

PAGE

1. Chi-square Indicating Differences Between

Groups on the Basis of Sex . . . . . . 18 


\section{CHAPTER I}

\section{INTRODUCTION}

The research community studying drug and alcohol abuse report that people suffering from addiction to chemical substances who remain in chemical dependency treatment, experience a significant rate of improvement as compared to those who drop out of treatment. support for this assumption is reported by Baeklund and Lundwall (1975) and by Bean and Karasievich (1975). When a treatment staff is more easily able to predict whether or not someone will drop out of treatment, efforts can be made to modify the treatment program in order to improve retention rates and therapeutic effectiveness (Baeklund and Lundwal1, 1975; Krasnoff, 1976). A person who drops out of treatment represents an inability for that particular program to provide treatment for the patients who may be most in need. (Baeklund and Lundwal1, 1975; Sladen and Mozdzierz, 1985). It is the objective of this investigation to attempt to identify factors which influence whether or not someone is likely to drop out of a chemical dependency treatment program. Dropping out of treatment is defined as someone who leaves treatment against medical advice (AMA).

Many studies have been performed which investigate personality traits and demographic characteristics of the 
"dropout." Researchers for most of these investigations use Veterans or state hospital treatment centers which contain a population different from the populations of non-hospital based programs (i.e., residential programs) even though study of residential programs are becoming more and more common in research (Baeklund and Lundwall, 1975; Pekaric, Jones and Blodgett, 1986). The objective of this investigation is to study a population from a private, nonprofit, residentially based medical program which is Independent of any mental health or community agency. This investigation wlll be modeled partly on a study by Pekarlc, and others (1986) performed at a residential treatment center in Kansas. That study will be described later.

\section{REVIEW OF THE LITERATURE}

In performing a complete search of the literature the author was able to find few up to date studies on treatment completion. Therefore, research dating as far back as 1973 was included as reference for the present study, including some studies on treatment outcome and a study which investigated matching treatment modalities to clients with the intent of providing information useful to the present work .

Previous research has indicated that certain demographic variables and personality test scores have value in predicting whether persons will complete treatment for substance abuse (Baeklund and Lundwall, 1975; Gross and 
Nerviano, 1973; Mozdzierz, Macchitell1, Conway, and Krauss, 1973; Ornstein and Cherepon, 1985; Pekaric, and others, 1986; Schuckit, schwei, and Gold, 1986; sladen and Mozdzierz, 1985).

In 1985, sladen and Mozdzierz developed an MMPI scale which would detect a high probablity of leaving treatment against medical advice. Their subject group consisted of 186 males who were patients in a Veterans hospital between 1978 and 1981. The inpatient program was four weeks long. They were able to isolate items from the MMPI which would indicate whether or not someone would leave treatment early, stating that the scale "appears to have useful potential." The qualification of "potential" must be noted. Gross and Nerviano (1973) insist that no conclusive evidence can be obtained which allows such a prediction from the use of MMPI scales.

Other studies have investigated the outcome of treatment using both MMPI and demographic data. Schuckit, Schweei, and Gold, (1986) gathered demographic data at intake, including marital status, occupational status, education, family history of substance abuse, psychiatric history, and age of first use and first problem with substances. The objective of the authors was to assess the ability to predict the one year outcome of treatment. Using stepwise regression analysis they evaluated the combinations of variables which would explain the variance on two outcome measures: abstention from use of chemical substances, and 
the "Clinical outcome score" which measures the patients" overall life adjustments and not just their use of alcohol. They explain that their ability to predict one year outcome from information gathered at intake was poor despite a large number of subjects, intake data gathered from multiple sources and a high percentage of successful follow-ups with face to face interviews.

Bean, Khantzian, Mack, Vaillant, and Zinberg used age, gender, and previous attempts at treatment when they investigated the impact of different treatment approaches on people from different circumstances (Bean, and others, 1981). McLellan, Woody and O'Brien, (1979) suggest that drug preference may be associated with pre-existing psychological conditions and therefore contribute to someone successfully completing treatment. Schuckit and others, (1986) investigated education, marital status, and history of abuse in their attempt to predict outcome of treatment.

In summarizing 45 studies, using 208 predictor variables, Gibbs and Flannlgan (1977) demonstrated that social class and occupation were successful predictors of a favorable outcome of treatment. Bromet, Moos, Wuthman and Bliss, (1977) studied the relationship between a patient's experience in treatment and characteristics of the patient. They found that social class, income, marital status, and stability of social life influenced this relationship. Finney and Moos (1986) attempted to define the issues 
related to matching a patient with a treatment program. They discovered that marital status, employment, and age play a significant role in making appropriate matchings. As stated above, the present study will be based on a work by Pekaric, and others (1986). The1r study Investigated the relationship of scores on four MMPI scales and certain demographic variables with whether or not a patient completed treatment. They considered that since a number of characteristics have been associated with dropping out, there was a better possibility that combinations of these variables could be predictors of treatment completion. The subject population was taken from a 21-day alcoholism treatment program located in a residential setting. The demographic data were gathered from preadmission interviews. The personality data were obtained from psychological tests which were routinely administered to all patients. They performed a correlational analysis and discovered that the Pd scale score of the MMPI was higher among dropouts than completors, indicating that dropouts experienced more anxiety and hostility toward authority than people who completed treatment. They also discovered a high negative correlation between the Pd scale score and age for the patients who completed treatment but not for those who dropped out of treatment. They state at the conclusion of their article that "further research with dropouts from such (residential) programs would assist our understanding of alcoholism treatment." 
The present investigator selected gendex, number of drugs used by the subject, drug preference, treatment history, marital success, education and social status, asvariables to be used in this investigation. Also, as a result of discussion with counselors working in the field, dependents living at home and method of admission were included as important potential influences on treatment completion. Each of these characteristics were available in the patient chart located at the treatment agency.

since the objective of this study is to identify variables which will allow prediction of completing treatment, only data collected from patients early in treatment were used. Of 65 patients who left treatment AMA between June 1987 and June 1988 at the agency investigated in this study, $42(64.6 \%)$ left in the first week and 17 (26.2\%) left in the second week, so $90.8 \%$ of all dropouts left in the first fourteen days.

People who dropped out of treatment within the first 4 to 10 days between 1985 and 1988 made the pool of subjects used in this investigation. The author selected people who attended the inpatient therapy group which begins after completing "detox" (generally the fourth day after entrance into the treatment agency) with the intent of studying subjects who decided to leave treatment after entering into the treatment phase of the program. The author used the tenth day as a cut off day because the patient will have been in treatment for one full week. Also, it is the 
objective of this investigation to detect dropping out at the earliest time possible. Although the MMPI is used as a tool of information within this treatment center it is often not administered within the flrst ten days of treatment. Therefore, MMPI scores cannot be included in the data gathered. 
CHAPTER II

\section{METHOD}

\section{SUBJECTS}

The subjects were patients from a private, non-profit chemical dependency program located in a resldential area of Eugene, oregon. Eugene is a university town with a population of approximately 105,000 people.

The files of the first 60 people who dropped out of treatment AMA between 1985 and 1988 were pulled by the file clerk at the treatment agency. Following the selection of people for the AMA group, every fifth person who completed treatment between 1985 and 1988 was selected unt 11 sixty people were chosen. The author abstracted the necessary data from each file and chose subjects to be used in the investigation based on whether their files were complete. subsequently, 45 subjects were chosen for each group.

\section{TREATMENT MILIEU}

The treatment center has space for 56 people in its inpatient program. The treatment program lasts an average of 28 days and addresses the addiction to alcohol and other drugs. The foundation for treatment at this agency is the 
Twelve step program. Twelve step programs offer people a lifestyle structure for them to use as they learn to live without drugs or alcohol (please refer to Appendix B for a list of the Twelve steps).

The intake and admission process includes a counselor intake and assessment, followed by a staff review. The Intake counselor determines whether or not a person is experiencing chemical dependency and recommends admission to the treatment facility. People who are diagnosed as mentally ill are not admitted, but are referred to other agencies in the community that address dual diagnosis. General treatment goals stress sobriety and development of community and family support systems.

Following the intake interview and assessment, the patient enters into the center's medical facility which oversees the patient's physical withdrawal from chemical substances ("detox"). Being a medical facility, the environment of "detox" resembles a hospital. The walls are bare, nurses are close by, the patient wears pajamas and the interaction with other patients is limited to those who are in "detox," except at meals. The length of stay in "detox" ranges from 1-3 days.

Upon discharge from "detox" the patient lives with other patients in a residential setting. The patient shares living space with another patient, similar to having a roommate in an apartment. Other patients come to visit and the patient is free to walk around the block or wander 
within the treatment facility during hours when program requirements are not scheduled.

On entry into the residential setting the patient begins the next phase of the treatment process. In the flrst week of residential treatment the patient attends educational lectures and inpatient group therapy. The groups consist of the patient's individual counselor and other patients who provide feedback and support for the patient's experience in treatment. During the first week following "detox" the patient also attends a "first step" group which offers the patient the opportunity to understand how one begins the process of recovery according to the Twelve step Program.

During the second week the patient writes a lengthy autobiography chronicling his/her use of chemical substances up to the point of entering treatment and reads it to the members of the inpatient group. The task of writing and then reading this autobiography is a process which attempts to focus the patient on his/her "powerlessness" over drugs referred to in the "first step." At the beginning of the third week in treatment the patient attends family group whlch focuses on family problems resulting from substance abuse. The patient's family members attend this group with permission of the patient.

The patient also attends individual therapy once a week beginning in the first week of treatment. Treatment plans reflecting goals which indicate progress in treatment are 
created for each patient during individual therapy. The patient is required to accomplish the goals within the treatment plan prior to the end of treatment. During treatment each patient must attend Alcoholics Anonymous and Narcotics Anonymous -- both of those programs are designed to support the addict in sobriety. Recreational activities are available and encouraged. Patients are also urged to attend house maintenance meetings which are a forum for the patients to express feelings about any aspect of the treatment program. The chair of the meetings then communicates these feelings to the person in charge of the treatment program.

In summary, the main sequence of events of the treatment program are as follows:

1st day

Patient is assessed during an intake interview.

1st through 3rd day patient is in detox.

1st week

Patient enters the residential

environment and begins "1st step" group and Inpatient group and attends educational lectures. All AMA subjects in the present study got at least this far in the program.

2nd week Patient attends Inpatient group, educational lectures and reads autobiography. 
3rd week

4 th week

Patient attends Family group, inpatient group and educational lectures.

Patlent attends Inpatient group, educational lectures.

\section{TREATMENT STAFF}

The staff of the treatment program includes five counselors with either Masters degrees or state certification or both. Each inpatient counselor has one intern assigned from a substance abuse counselor training program located at and funded by the agency. Each counselor is supervised by the program manager who is a state certified drug and alcohol counselor. Chaplains are available to address spiritual and moral issues the patient may be hesitant to talk about with a lay person.

\section{PROCEDURE}

Two groups of 45 patients were selected from the inpatient population. One group, the completed Treatment group, comprised patients who had completed the 28 day program. The second group, the AMA Discharge group, comprised patients who dropped out of treatment within the first four to ten days. Completing treatment is defined as a person who has undergone treatment and is discharged as "treatment completed." Dropping out is defined as someone 
who leaves treatment against medical advice (AMA). Each subject had attended the patient group and the first step group. Demographic data on each subject was gathered from the charts on flle for the patients.

\section{MEASURES}

\section{Demographic Variables}

The following demographic variables were analyzed:

Gender (GEN)

Number of Drugs (NDRUG)

Drug Preference (DPREF)

Method of Admission (ADM)

Treatment History (TXHX)

Marital success (MST)

Social status (EST)

Dependents Living at Home (DEP)

Education (ED)

Demographic data were obtained from the structured intake interview recorded in the patient's chart. A definition of each variable follows. Please refer to Appendix $A$ for information on the scoring method and the range of scores for each variable.

Gender (GEN). This indicates the sex of the subject. Number of Drugs (NDRUG). This variable indicates whether the subject used one or more different drugs. Drug Preference (DPREF). This indicates whether alcohol, cocaine, marijuana, methamphetamine, heroin or 
other was the chemical substance preferred most by the patient. Heroin was ranked highest with cocaine, methamphetamine, alcohol, marijuana and other ranking in order of destructiveness.

Method of Admission (ADM). This varlable is defined by the manner in which the patient was referred to treatment, i.e., self-referred, employment referred, court mandated, doctor referred, or if the patient came to treatment as a result of an intervention. For the purpose of data analysis the author ranked method of admission in terms of degree of mandate influencing the subject to enter treatment. The method ranked lowest was self admission indicating the least degree of mandate, followed by doctor referred, family intervention, employment mandate and court mandate.

Treatment History $(T X H X)$. This variable indicates the number of times the patient previously particlpated in a substance abuse treatment program.

Marltal Success (MST). This variable was defined by the author to indicate success in maintaining a relationship, according to the person's experience with a long term commitment. A person who was single was ranked lowest on the scale followed by a person who was divorced, separated, married or widowed.

Social status (EST). The sociometric Approach to Status Measurement (Nam and Powers, 1983) was used to determine. Nam and Powers created occupational status 
scores for 589 occupations incorporating education, occupation and income as three essential determinants of social status.

\section{Dependents Living at Home (DEP). This variable} represents a record of the number of people dependent on the subject living in the same home with the subject.

Education (ED). This indicates the number of years the subject attended school. 
RESULTS

Descriptive statistics were obtained on all variables for both groups (people who completed treatment and people who left treatment $A M A)$ and for the total sample. The means, standard deviation and t-tests are listed in Table I.

TABLE I

GROUP MEAN, STANDARD DEVIATION AND $t$-TEST FOR ALL VARIABLES Variable Completed Treatment Group $\quad \mathrm{N}=45$

AMA Discharge

Group $N=45$ $\mathbf{x}$

3.1

2.0

1.8

.33

2.6

$2.9 \quad 1.3$

48.422 .8

$.78 \quad .93$

12.62 .0

11.8

$1.7 \quad 1.0$ $\mathrm{sd}$ $t *$

DEP

ED ta11)

$\begin{array}{lrrrrrr}\text { EST } & 48.4 & 22.8 & 39.8 & 24.2 & 1.75 & .084 \\ \text { DEP } & .78 & .93 & .58 & 1.1 & .96 & .342 \\ \text { ED } & 12.6 & 2.0 & 11.8 & 3.0 & 1.46 & .147\end{array}$

* $\mathrm{df}=88$ for all variables 
Gender is not included in the table because that variable is scored on a nominal scale (male or female). A chi-square test was performed to determine whether there was significant difference between the two groups of subjects on the basis of sex (see Flgure 1). With $1 \mathrm{df}$, ch1-square = .82949 with $p=.362$ indlcating no signiflcant difference between the two groups in their proportions of men and women subjects.

The t-tests show the significance of the difference between the means of the two groups on each variable. The sign of $t$ indicates the directionality of the difference. For instance, $t=-.84$ on DPREF in the AMA Discharge group. Note that $x=2.9$ in the completed Treatment group and $x=3.1$ in the AMA Discharge group. The fact that $x$ for the first group is less than $x$ for the second group is indicated by the negative sign of $t$. A positive value of $t$ indicates the larger mean value for the completed Treatment group. 
CHI-SQUARE INDICATING DIFFERENCES BETWEEN GROUPS ON THE BASIS OF SEX

WOMEN

COMPLETED

TREATMENT

MEN

AMA

Row

DISCHARGE Total

GP

COMPLETED TREATM

AMA DISCHARGE

\begin{tabular}{|l|l|}
\hline 12 & 33 \\
\hline 16 & 29 \\
\hline
\end{tabular}

Column

Total

28

62

45

50.0

45

50.0

31. 1

68.9

100.0

Chi-square

Value

DF

Significance

Pearson

.82949

1

.36242

Fiqure 1. Chi-square indicating differences between groups on the basis of sex.

\section{DISCRIMINANT ANALYSIS}

A stepwise discriminant analysis using the sSPS- $x$ statistical package was performed to select the best linear, weighted combination of variables which would produce the greatest discrimination between the two groups. The criterion for including a variable in the discriminant function was Wilk's Lambda (L). Table II shows the wilk's 
Lambda and F-Ratio for each viable before the first step of the discriminant analysis. The program-selected variables were chosen according to smallest L. A Lambda of 1 occurs when group means are equal. Values close to 0 occur when most of the total variance of a variable is attributable to differences between the means of the groups.

\section{TABLE I I}

WILK'S LAMBDA, F-RATIO AND SIGNIFICANCE FOR EACH VARIABLE BEFORE THE FIRST STEP OF DISCRIMINANT ANALYSIS

\begin{tabular}{lccc} 
Variable & Wilk's Lambda & F-Ratio* & Significance \\
\hline GEN & .99078 & .8186 & .3681 \\
DPREF & .99210 & .7008 & .4048 \\
NDRUG & .98175 & 1.636 & .2042 \\
ADM & .99527 & .4182 & .5195 \\
TXHX & .97516 & 2.242 & .1379 \\
MST & .98289 & 1.532 & .2191 \\
EST & .96638 & 3.062 & .0836 \\
DEP & .98973 & .9129 & .3420 \\
ED & .97623 & 2.143 & .1468
\end{tabular}

$* d f=1,88$ for all variables

If one refers to Table II, one is able to choose which variables are likely to be discriminant. For instance, EST, TXHX, MST, NDRUG, and ED have the lowest $L$ values and the highest significance levels indicating the likelihood that they will be discriminant variables. 
A Box's $M$ test was performed on the data for equality of covariances in the two groups. This test determines if the two groups are similar enough for a valid discriminant function to be performed. Table III shows that the covariance for the two groups are not equal at a significance level of .0054 . This makes the discriminant function liable to error in classifying group members correctly. However, since the sample size is relatively large ( 45 subjects per group) that fallibility is reduced.

TABLE I I I

TEST OF EQUALITY OF GROUP COVARIANCE USING BOX'S M Group Labe 1

o Completed Treatment Rank Log Determinant

1 AMA Discharge 4

4.064536

Pooled Within Groups

Covariance Matrix

4

5.478252

\begin{tabular}{ccccc} 
Box's $M$ & Approximate $F$ & Degrees of Freedom & signiflca \\
26.8 & 2.4984 & 10, & 37023.1 & 0.005 \\
\hline NOTE: The ranks and natural logarithms of determinants
\end{tabular} printed are those of the group covariance matrices.

Since interdependencles among the variables affect multivariate analyses, it is worth examining the correlation matrix of the predictor variables.

Looking at Table IV one notices that social status is not related to Gender but is related to Education. The 
more education someone receives, the higher the likelihood of obtaining a higher social status. One is also able to see that Marital success is related to Dependents Living at Home. When one sustains a relationship one often has children from that relationship. These correlations are artifacts of the measures and do not provide much information. However, note the relationship between Drug Preference and Marital Success and Social status. Also, a relationship between social status and Number of Drugs is apparent. These relationships indicate a possible connection between substance abuse and whether or not someone is involved in an occupation with status in the community and/or 1 s capable of malntalning a personal partnership with another person. 
TABLE IV

POOLED WITHIN-GROUPS CORRELATION MATRIX

\begin{tabular}{lllll} 
GEN & DPREF & NDRUG & ADM & TXHX \\
\hline
\end{tabular}

\begin{tabular}{|c|c|c|c|c|c|}
\hline GEN & 1.00000 & & & & \\
\hline DPREF & -0.06402 & 1.00000 & & & \\
\hline NDRUG & 0.10939 & -0.19885 & 1.00000 & & \\
\hline$A D M$ & -0.14627 & -0.07536 & 0.09155 & 1.00000 & \\
\hline TXHX & 0.05196 & -0.07434 & 0.12712 & -0.12378 & 1.00000 \\
\hline MST & -0.02291 & 0.29438 & -0.13477 & -0.04834 & 0.10214 \\
\hline EST & -0.05381 & 0.25289 & -0.24884 & -0.07572 & 0.01693 \\
\hline DEP & -0.10860 & 0.11135 & -0.01824 & 0.07311 & -0.04290 \\
\hline ED & -0.05698 & 0.21089 & -0.13375 & -0.19539 & 0.02758 \\
\hline & MST & EST & DEP & ED & \\
\hline
\end{tabular}

GEN

DPREF

NDRUG

ADM

TXHX

MST $\quad 1.00000$

EST $\quad 0.17223 \quad 1.00000$

$\begin{array}{lrrrr}\text { DEP } & 0.27535 & -0.05428 & 1.00000 & \\ \text { ED } & 0.18944 & 0.53068 & -0.15289 & 1.00000\end{array}$

At the beginning of each step of the discriminant analysis, each selected variable is tested to determine whether to amount of intergroup variance it accounts for is 
significant in terms of $\mathrm{L}$. If one varlable contributes the same information previously contributed by another variable, the variable contributing less of this same information is dropped. The end result of the analysis is the optimal set of variables with non-redundant information which best separates the two groups. The two groups were compared on all 9 of the varlables. After 4 steps of the analysis, 4 of the 9 variables proved to be discriminant and are listed in Table V.

\section{TABLE V}

WILK'S LAMBDA AND SIGNIFICANCE FOR DISCRIMINATING VARIABLES AFTER 4 STEPS

Variable

social status

Treatment History

Drug Preference

Marital success
Wilk's Lambda

.96638

.94224

.92145

.89835
Slgniflcance

.0836

.0752

.0695

.0559

The variables whlch were eliminated are as follows: Gender, Number of Drugs, Method of Admission, Number of Dependents Living at Home, Education Level.

\section{DISCRIMINANT FUNCTIONS}

As the Elnal step in discriminant analysis, standardized canonical discriminant function coefficients were derived from the varlables found to be discriminating 
of the two groups. Each coefflcient, shown in tablew VI reflects the weighted contribution of a variable to the linear discriminant function; the positive and negative slgns indicate direction only.

TABLE VI

STANDARDIZED CANONICAL DISCRIMINANT FUNCTION CEOFFICIENTS Varlable Discriminant Weight of Variable

Drug Preference 0.62359

Treatment History 0.58538

Marital success $-0.52687$

Social status $-0.63139$

These 4 variables proved to be significant in accounting for the greatest proportion of total varlance at a significance level of .0559, a close approach to the usual accepted level of .05 . The discriminant function was dominated positively by Drug Preference and negatively by Social status.

The discriminant function was used to classify the individual subjects according to their highest probability of membership into each group, as shown in table VII. 


\section{TABLE VII}

RESULTS OF DISCRIMINANT CLASSIFICATION OF SUBJECTS INTO GROUPS

Actual Group

No. of

cases
Predicted Group Membership Completed
Treatment
AMA
Discharge

\begin{tabular}{lccc}
\hline Completed Treatment & 45 & 31 & 14 \\
& & 68.98 & $31.1 \%$ \\
AMA Discharge & 45 & 16 & 29 \\
& & 35.68 & 64.48
\end{tabular}

Percent of cases correctly classified: $\quad 66.67 \%$

By comparing actual and predicted group memberships, using the original sample, the validity of the discriminant function and discriminant variables was empirically measured. People who completed treatment were correctly predicted $68.9 \%$ of the time to complete treatment. Those who left AMA were correctly predicted $64.4 \%$ of the time to drop out of treatment AMA. The percent of all "grouped" cases correctly classified by the discriminant analysis was 66.678 . 
CHAPTER IV

\section{SCUSSION}

This study was undertaken to explore the possibility of predicting whether or not someone entering into substance abuse treatment was Ilkely to drop out before completing treatment. Dropping out of treatment is a concern shared by administrators and counselors alike in the field of substance abuse. For the administrator, it is important to maintain a reputation for effectiveness of treatment in order to compete with the other treatment programs in the area. If a consistently large percentage of people drop out of a particular agency then that agency will suffer in its reputation for effectiveness. For the counselors working in the treatment agency, when someone leaves treatment AMA it is considered a loss of an opportunity to help the client.

People responsible for developing insurance policy and establishing state funding levels for treatment also share this concern. It is necessary to establish realistic opportunities for those suffering from destructive abuse to recelve help and at the same time maintain the cost effectiveness of the program.

It can be seen in Table III that, on the first step of the discriminant analysis, the variable social status would be selected as the first predictor. Note that social status 
has an L of .96638 , the lowest $L$ of the 9 variables. The Wilk's Lambda test was performed after each variable was selected as a discriminant. The $L$ for the remaining variables becomes a different number when the discriminant variable is excluded from the variable selection.

At the next step, the analysis selected Treatment History as the next highest ranking variable to account for variance between groups. The significance level of the combined variables of social status and Treatment History was .0752 . Out of the 7 remaining variables the analysis selected Drug Preference as ranking third in its impact on variance between groups and the significance level of the combined three was .0695 . Finally, the analysis selected Marital success as the fourth ranking variable to influence the variance between groups. These 4 variables, linearly combined with the assigned welghts, allowed the best possible prediction of group membership. The probability that such a discriminant function would be found by chance is .0559. Five variables did not contribute enough to the discrimination between the groups to be included in the analysis.

The ANOVA of discriminant scores indicates that the discriminant function differentiates the two groups at a significance level of .0022 as shown in Table VII. The ANOVA shows that if each subject is measured by his or her indiscriminant score then the correct assignment of subjects to each group is better than chance. This illustrates 
statistical slgnificance. However, in the practical application of the discriminant function, if one predicts correctly that a person will drop out of treatment between 608 and $70 \%$ of the time, then for 30 to 40 out of 100 patients the prediction will be wrong. One must consider the consequences of being wrong in this particular circumstance.

TABLE VIII

ANOVA OF DISCRIMINANT SCORES DIFFERENTIATING BOTH GROUPS

$\begin{array}{lccccc}\text { Source } & \begin{array}{r}\text { Sum of } \\ \text { Squares }\end{array} & \text { D.F. } & \begin{array}{c}\text { Mean } \\ \text { Square }\end{array} & \text { F } & \text { Sig } \\ \text { Between Groups } & 9.9572 & 1 . & 9.9572 & 9.9572 & .0022 \\ \text { within Groups } & 88.0000 & 88 & 1.0000 & & \end{array}$

$$
\text { Eta }=.3188 \quad \text { Eta squared }-.1016
$$


one of the objectives of this study was to discover if a combination of characteristics could predict whether or not someone would drop out of treatment. It is true that a discriminant analysis has, in fact, separated out four characteristics which have a greater than chance ability to predict treatment completion. However, the clinical use of the discriminant function is not recommended because of the consequences of being wrong. A person who requests treatment may have the characteristics which predict that he or she will drop out of treatment but that person may be one of the 30 to 40 who would complete treatment but be misclassified by the discriminant procedure. If a treatment staff determined that the person is a high risk for dropping out of a treatment program and did not admit them to treatment on that basis then that person would be kept from experiencing the possible advantages of treatment.

Most of the people who were correctly included into the AMA group tend to be addicted to a self-destructive substance, are ranked low on Marital success, receive a low social status score and have been involved in treatment at least once previously. Those subjects who were correctly included in the completed treatment group tend to be addicted to a less self-destructive substance, have experienced no previous treatment, are ranked high on Marital success and receive a high social status score. When a subject was misclassified, the statistical profile of that person was similar to those in the group to which they 
were assigned but the person did the opposite of what was expected. Because between $30 \%$ and $40 \%$ of the sorted people might do the opposite of what is expected, the discriminant variables isolated by the discriminant analysis are not clinically useful.

\section{IMPLICATIONS FOR FURTHER STUDY}

one might raise some legitimate questions which were not addressed in this investigation. For instance, it is common for people to assume that some personal deficit or condition causes a person to drop out of substance abuse treatment. This study approaches predicting dropping out of treatment from this perspective.

However, what of the interactive qualities of the client and the treatment program? Might there be something about the structure of the treatment program that might alienate a person entering into treatment? If one views experience from a systems perspective, the nature of the interaction between the treatment program and the client is significant. It becomes necessary to consider aspects of the program in relationship to the perceptions of the client in order to draw an accurate conclusion about client behavior.

For example, imagine that a person comes in for treatment. Their first stop is the medical facility where s/he goes through "detox." $s /$ he is given pajamas which $s /$ he wears until s/he is discharged from "detox." In this way 
s/he is segregated from the rest of the population, both by wearing pajamas and by location. The "detox" facility is physically separate from the residential living quarters of the other patients.

Imagine that a person used to a high-ranking position -perhaps an executive in a company -- enters treatment. She is used to giving orders, to being deferred to by employees, to being in control of the impression she gives to others. She does not share her private life with others. Suddenly, she is in pajamas while others are dressed in street clothes, is being constantly monitored by others, and has her behavior regulated by the rules of the agency.

Although this person may fit the statistlcal proflle of someone who would complete treatment, it is important to consider the possible impact of the environment on her as an individual. She might feel angry and resentful because the program staff are acting toward her as if she is not someone with power and influence. She may also feel anxious and humiliated by her lack of privacy. She may declde to leave treatment AMA.

Entering into treatment is a shock to someone's emotional and physiological system. Feelings of defensiveness, anger and loneliness are common. Is it possible to alleviate the stress brought about by the contrast between private life and the new experience of the treatment structure? Perhaps a support or entry group which 
would address the initial experience of someone entering treatment, or a discussion of these issues during the intake interview would be an addition of value to the treatment admission process.

Or what about the experience of the patient when confronted with the steps of the Twelve step Program which represents the philosophical foundation of the treatment program? The phrase "God, as you understand him" appears in the third step and is repeated in steps 5, 6, 7 and 11 . The client becomes aware of the Twelve steps when they first enter treatment. Twelve step programs go to great length to clarify the definitive difference between a spiritual and a religious framework in relationship to the twelve steps, yet some people will respond negatively to the idea of "God" however the term is defined. It is true that God, according to the Twelve step programs, may be the power of a group of people, or natural forces, or the wind. However, a client may have a feeling or opinion about "God" which presents an obstacle to one's attempts to engage in the program as required by the treatment agency.

An aspect of the intake interview, administered previous to admission, is the religious preference of the client. Rather than simply gathering information on religious preference, perhaps information about the client's thoughts and feelings toward spiritual and religious experience would offer more understanding of the person's response to the philosophical basis of treatment and also 
provide an opportunity for the admissions counselor to learn about how the client will respond to the Twelve step Program.

\section{CONCLUSIONS}

The variables selected for this study do not predict dropping out of treatment at a level of certainty which is clinically useful. However, the inadequacy of the findings do raise questions for further research. The statistics do support accurate prediction for a person to drop out of treatment $66 \%$ of the time, however, the truth is that most treatment centers have a smaller percentage of people dropping out of treatment AMA than 348. Therefore, using the evidence gathered in this study as a predictive tool would not be useful. What becomes clear to the author is that static demographic variables provide no more information than is already used by the treatment agency. Instead, studying the role of variables which represent the patient's interaction with the treatment program might better benefit the agency. For instance, recording the patient's response to the program at different points during treatment offers information about how the patient perceives treatment. Such information might cast light on the patient's tendency to complete treatment or to leave before finishing.

Perhaps a treatment program can focus more on the Intake interview and incorporate into it a candid discussion 
of how the environment of the treatment center differs from the home environment of the patient. From this intake interview more information derived from the "experience" of the patient entering into treatment can be gathered and data on treatment completion can be obtained that can lead to results that are clinically useful.

It is the recommendation of the author that the efforts of an agency be concentrated on altering the program in a way to insure program completion of the client rather than accurately predicting who will or will not drop out of treatment and discriminately admitting those who will successfully complete treatment. Even if the results obtained by this study accurately predicted dropping out of treatment $100 \%$ of the time, the focus must not be on discriminately choosing to admit those people who will not drop out of treatment but instead on what the agency can do to enable a person to complete treatment. This may sometimes require the redesign of treatment programs. 
REFERENCES

Alcoholics Anonymous: The story of How Many Thousands of Men and Women Have Recovered from Alcoholism. (1976). Third Edition. Alcohollcs Anonymous World Services, Inc. New York, New York, p. 59-60.

Baeklund, F. and Lundwall, L. (1975). Dropping out of Treatment: Review. Psychological Bulletin, 82, no. 5, p. $738-767$.

Bean, M., Khantzian, E., Mack, J., Valllant, G., Zinberg, N. (1981). Dynamic Approaches to the Understanding and Treatment of Alcoholism. New York: Free Press.

Bean, M. and Karasievich, G. (1975). Psychological Test Results at Three stages of Alcoholism Treatment. Journal of Studies on Alcohol, 36, p. 838-852.

Bromet, Moos, R., Wuthman, C., and Bliss. (1977). Treatment Experiences of Alcoholic Patjents: An Analysis of Five Residentlal Treatment Programs. The International Journal of the Addictions, 12, no. 7, p. 953-957.

Emrick, C. (1975). A Review of Psychologically orlented Treatment of Alcoholism. Journal of Studies on Alcohol, 36, no. 1, p. 88-99.

Finny, J. and Moos, R. (1986). Matching Patients with Treatments: Conceptual and Methodological Issues. Journal of studies on Alcohol, 47, no. 2, p. 1222-123.

Gibbs, L. and Flannigan, J. (1977). Prognostic Indicators of Alcoholism Treatment Outcome. The International Journal of the Addictions, 12, p. 1097-1141.

Gross, W.F. and Nerviano, V.J. (1973). The Prediction of Dropouts from an Inpatient Alcohollsm Program. Quarterly Journal of Studies on Alcohol, 34, p. 514-515.

Krasnoff, A. (1976). Differences Between Alcoholics who Complete or withdraw From Treatment. Journal of studies on Alcohol, 57, p. 1666-1671.

Mcclellan, T., Woody, G., and O'Brien, C. (1979). Development of Psychiatric Illness in Drug Abusers. The New Enqland Journal of Medicine, 301, p. 13110-1314. 
Mozdzierz, G., Macchitelli, F., Conway, J. and Krauss, H. (1973). Personality Characteristics of Alcoholics Who Leave Treatment Against Medical Advice and Those who Don't. Journal of Clinical Psychology, 29, p. 78-82.

Nam, C. and Powers, M. (1983). The Sociometric Approach to status Measurement. Houston: Cap and Gown Press.

ornstein, P. and Cherepon. (1985). Demographic Variables As Predictors of Alcoholism Treatment outcome. Journal of Studies on Alcohol, 46 , no. 5, p. 425-431.

Pekaric, G., Jones, D. and Blodgett, C. (1986).

Personality and Demographic Characteristics of Dropouts and Completors in Nonhospital Residential Alcohol Treatment Program. The International Journal of the Addictions, 21, no. 1, p. 131-137.

Schuckit, M., Schwei, M. and Gold, E. (1986). Prediction of outcome in Inpatient Alcoholics. Journal of studies on Alcohol, 47, no. 2, p. 151-155.

Sladen, B. and Mozdzierz, G. (1985). An MMPI to Predict Premature Termination. Journal of Clinical Psychology, 41, no. 6, p. 855-862. 


\section{APPENDIX A}

DESCRIPTION OF THE NUMERICAL RANKING OF EACH VARIABLE

Gender received either a 1 indicating male or a 0 indicating female.

Number of Drugs recejved a $1,2,3,4,5$, or 6 indicating the number of different drugs used by the subject.

Drug Preference was indicated by a $1,2,3,4$, or 5 indicating the degree of destructiveness. Each drug was ranked by asking six people involved in the substance abuse field how they would judge each drug according to the perception of self destructiveness. Number 1 indicates the highest degree of destructiveness and number 5 reflects the lowest degree of destructiveness.

Heroin $=1$

Cocaine $=2$

Methamphetamine $=2$

Alcohol $=3$

Marijuana $=5$

other $(e . g .$, caffeine, nicotine $)=6$ 
Method of Admission received a $1,2,3,4$ or 5 reflecting the degree of mandate influencing the subject to enter treatment. One indicated the least degree of mandate and five indicated the highest degree of mandate.

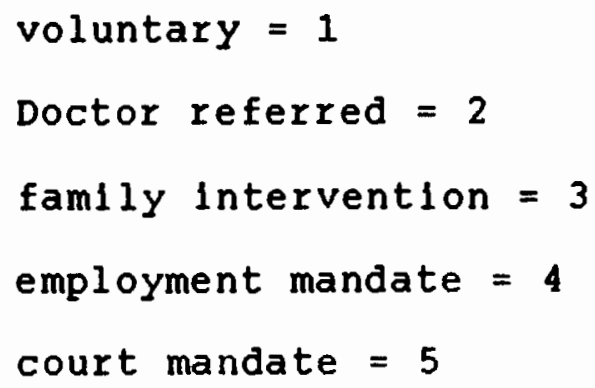
participated in previously.

Marital success was ranked according to success in maintaining a relationship. One indicated the least success and 4 reflected the most success.

$$
\begin{aligned}
& \text { single }=1 \\
& \text { divorced }=2 \\
& \text { separated }=3 \\
& \text { married or widowed }=4
\end{aligned}
$$

social status was given numbers used by Nam and Powers in The sociometric Approach to status Measurement (1983).

Dependents Living at Home was represented by a numerical record of the number of people dependent on the subject living at home.

Education was represented by a numerical record of the number of years the subject attended school. 


\section{APPENDIX B}

LIST OF THE TWELVE STEPS (ALCOHOLICS ANONYMOUS, 1976)

1. We admitted we were powerless over alcohol -- that our lives had become unmanageable.

2. Came to believe that a Power greater than ourselves could restore us to sanity.

3. Made a decision to turn our will and our lives over to the care of God as we understood Him.

4. Made a searching and fearless moral inventory of ourselves.

5. Admitted to God, to ourselves, and to another human being the exact nature of our wrongs.

6. Were entirely ready to have God remove all these defects of character.

7. Humbly asked Him to remove our shortcomings.

8. Made a list of all persons we had harmed, and became willing to make amends to them all.

9. Made direct amends to such people wherever possible, except when to do so would infure them or others.

10. Continued to take personal inventory and when we were wrong promptly admitted it. 
11. Sought through prayer and meditation to improve our conscious contact with God as we understood Him, praying only for knowledge of His will for us and the power to carry that out.

12. Having had a spiritual awakening as the result of these steps, we tried to carry this message to alcoholics, and to practice these principles in all our affairs. 